\title{
A Study on Prevalence of Alcohol Dependence in Coimbatore District
}

\author{
Helena Selvakodi Maria Louis ${ }^{1}$, Anandakrishna Kumar Somasundaram², Meenachi Swamynathan ${ }^{3}$, \\ Divya Bhathini Vaikuntavasan ${ }^{4}$ \\ ${ }^{1}$ Department of Psychiatry, District Mental Health Programme, Government Headquarters \\ Hospital, Pollachi, Coimbatore, Tamilnadu, India. ${ }^{2}$ Department of Psychiatry, Government Theni \\ Medical College, Theni, Tamilnadu, India. ${ }^{3}$ Department of Community Medicine, Government \\ Madurai Medical College, Madurai, Tamilnadu, India. ${ }^{4}$ Department of Community Medicine, \\ Karpagam Faculty of Medical Sciences and Research, Coimbatore, Tamilnadu, India.
}

\section{ABSTRACT}

\section{BACKGROUND}

India is considered to be the largest market for alcoholic products in the world with estimated 62.5 million alcohol users in 2005. There has been a rapid proliferation of bars and people are fast shedding the inhibitions over alcohol as a lifestyle choice. This study was conducted to determine the prevalence of alcohol dependence with relation to biopsychosocial factors as there is paucity in prevalence studies in India.

\section{METHODS}

This is a cross sectional study, in which 500 people in 25 villages in 3 blocks out of 13 blocks in Coimbatore district were selected by multistage cluster sampling method. The study was conducted over a period of 3 months from November 2019 to January 2020.

\section{RESULTS}

A total of 500 people was interviewed. Our study showed a prevalence of $44 \%$ of alcohol dependence and also has statistical significance with biopsychosocial factors.

\section{CONCLUSIONS}

Enforcement of laws pertaining to drinking, focussing on supply reduction, legal limits for alcohol intake with age restriction and health promotion activities by community level awareness should be considered to lower the prevalence of alcohol dependence in future.

\section{KEY WORDS}

Prevalence Alcohol Dependence, Biopsychosocial Factors with Alcohol
Corresponding Author:

Dr. Anandakrishna Kumar Somasundaram, Plot No. 14, Muthamil Nagar, $3^{\text {rd }}$ Street,

P \& T Nagar, Madurai-625017,

Tamilnadu, India.

E-mail: dr.anandakrish@gmail.com

DOI: 10.14260/jemds/2020/494

How to Cite This Article:

Louis HSM, Somasundaram AK, Swamynathan $M$, et al. A study on prevalence of alcohol dependence in Coimbatore district. J Evolution Med Dent Sci 2020;9(31):2279-2283, DOI: 10.14260/jemds/2020/494

Submission 27-04-2020,

Peer Review 19-06-2020

Acceptance 26-06-2020,

Published 10-08-2020.

Copyright (C) 2020 JEMDS. This is an open access article distributed under Creative Commons Attribution License [Attribution 4.0 International (CC BY 4.0)] 


\section{BACKGROUND}

Alcoholic products known since Vedic period, are used for worship purposes and for medicinal preparation. ${ }^{[1,2]}$ But now, Alcohol is considered as the main cause of death and causing 3.3 million deaths every year.,[3,4] It has been noted from the studies that $5.1 \%$ of global burden of disease are found to be due to consumption of alcohol. In south east Asia, alcohol consumption has increased by $50 \%$ between $1980-2000$. It is proved that countries with low alcohol intake are now witnessing an increasing consumption pattern. WHO estimates for the South East Asian countries indicate that onefourth to one-third of male population drink alcohol with increasing trends among women. The Lancet found that alcohol was the third main risk factor for death and reasonable for $5.5 \%$ of disability-adjusted life years lost globally, i.e., 136 million years of life lost due to dying early or living with an alcohol-related disability. Based on 2010 data, alcohol is ranked 3rd in terms of risk with high blood pressure and smoking. Alcohol -related cancer cases 4.6 million in worldwide, 1.9 million in developed countries, 2.8 million in less developed countries are estimated.

In developing countries like India, alcohol consumption is considered as an important public health problem. In India, per capita alcohol consumption has increased by $106.7 \%$ between 1970-1972 and 1994 to 1996. In National household survey 2004 had reported that, $21 \%$ of adult males and $<5 \%$ among females are consuming alcohol. The prevalence rate is the lowest $7 \%$ in the western part of Gujarat and the highest $75.0 \%$ in Arunachal Pradesh. In Southern India, the prevalence of alcohol use has varied between $33 \%$ and $50 \%$. Alcohol consumers in 2005 were 62.5 million with $17.4 \%$ are dependent users and $20-30 \%$ are hospitalised due to alcohol induced health issues. [5] WHO report on highest prevalence $17.1 \%$ was among $46-55$ years age group especially in males. Alcohol consumption in India between 2008-2012, increased to $30 \%$ of general population in $2010 .{ }^{[4]} 29.3 \%$ were alcohol dependent in 2013.[5] Recently, a study which was conducted in Kolkata among men, reported the prevalence of alcohol users to be $65 \%$ while a Vellore study reported prevalence of alcohol intake as $34.8 \%$. A study which was done in Faridabad showed the prevalence of alcohol use as $1.3 \%$ among females. Males especially adult age group were found to be independently associated with an increased risk of alcohol use. In another study, it was found that illiterates and people with lower educational levels were found to be associated with an increased risk of intake of alcohol in the general population. A recent study highlighted that in India, health related problems due to alcohol consumption will grow even larger, unless effective interventions and policies are implemented to reduce these habits.

In Tamilnadu, in previous south Indian studies it was noted $76.8 \%$ harmful use of alcohol with $95 \%$ confidence interval [71.1\%-81.7\%] and $12.4 \%$ alcohol dependence. This present study targeted Coimbatore district in Tamilnadu and from this present study we may get how many of users began drinking before 20 years, current prevalence of alcohol dependence and which sociodemographic variables have strong temporal relationship with alcohol dependence.
The present study aims to find out the current prevalence of alcohol dependence with sociodemographic variables and the influence of biopsychosocial factors with alcohol dependence in Coimbatore district.

\section{METHODS}

Our present study is a Cross sectional study, which was done in Coimbatore district in Tamilnadu in India. The study done in male population in Coimbatore in 25 villages pertaining to 3 block primary health centres namely Madukarai, Anamalai, Sarkarsamakulam block primary health centres. This study done for 3 months duration from November 2019 to January 2020.

\section{Inclusion Criteria}

1. Age 13 and above.

2. Only one adult in each house is taken for study and in the presence of $>1$ adult, anyone is randomly selected.

\section{Exclusion Criteria}

1. Sensory impairment.

2. Mentally retarded.

3. Persons not willing to give consent.

The following tools were used in this study. CAGE questionnaire used as a screening tool for Alcohol use. AUDIT [Alcohol Use Disorders Identification Test] used to categorize individuals either as with harmful use or alcohol dependenceAUDIT Questionnaire is a 10-item tool, proposed by WHO to assess patterns of drinking under 2 domains namely harmful alcohol use, alcohol dependence. All the questionnaires are measured by 4-point Likert scale which scores from 0 to 4 . Out of total score of 40; 8 and above indicates harmful use of alcohol and above 15 in men indicates alcohol dependence. SADQ [Severity of alcohol dependence questionnaire] which is used to classify as mild with score $<16$, moderate with score 16-30, and severe with score 31. PSS [Perceived stress scale] is used to measure biological, psychological and social stress which includes low stress with the score 0 to 13 , moderate stress with the score 14 to 26 , and high stress with score 27 to 40 and a Modified B.G. Prasad's socioeconomic scale based on monthly income of either the concerned person or head of his family member which includes upper class [Rs $7000 \&$ above], upper middle [3504-7007],middle [2102-3503],lower middle [1051-2101] and lower classes [1050 \& below]. A Structured questionnaire was used to collect information from the population regarding the details with certain social factors and along with history of alcoholism.

\section{Operational Definitions}

- *Dependence- On applying AUDIT questionnaire, the cut off and above 15 score was considered as alcohol dependence.

- *Stress-In a medical or biological context stress is explained as a physical, mental or emotional factor that 
causes bodily or mental tension. Stresses can be external [from the environment, psychological, or social situations] or internal [illness or from a medical procedure]

In this study, multistage cluster sampling was adopted, and 3 blocks were randomly selected from all 13 blocks. Then 25 villages out of 225 villages were selected from those 3 blocks by probability proportionate to size. Proposed sample size is 500 [25 clusters $x$ 20]. It is calculated with Epi info software by using following assumptions. Expected prevalence 20\%, allowable error of $5 \%$, design effect of 2 , Number of clusters 25 .

\section{Statistical Analysis}

The received data from participants were applied into Epi info software and statistical analysis like Chi-square and proportions were done in this study. Chi -square test is done to find out any association between the exposure [independent variables] and the outcome [alcohol dependence] in our study. Odds Ratio is a cross product ratio wherein we find out the association of the risk in exposed group to the non-exposed group. OR $<1$ has negative association i.e., risk in exposed is lesser than the risk in nonexposed, $\mathrm{OR}>1$ has positive association i.e., risk in exposed is greater than the risk in non-exposed

This study was approved by an institutional Ethical committee at Pollachi Government Hospital at Coimbatore district. Data has been collected by house to house survey in the village. After detail explanation of the study procedure to the participants, the investigator received a written informed consent from them. Using a structured interview schedule the participants were interviewed by the investigator which was mentioned in tools used for the study. Confidentiality was ensured before the conduct of interview.

\section{RESULTS}

Table 1 reveals, out of 500 individuals, 33.40\% are above 50 years of age and $9.80 \%$ are between 13 to 18 years. $97 \%$ are from rural and 3\% are from urban. 38\% are illiterate and $9.80 \%$ are degree holders. $76.60 \%$ are unskilled workers while $0.60 \%$ are professionals. $76.20 \%$ are unmarried while $23.80 \%$ are married. $61.60 \%$ are having family history of alcohol intake while $38.40 \%$ are not with the family history. $81.80 \%$ are not having mental illness while $2.60 \%$ are with anxiety and $0 \%$ are for schizophrenia. $87 \%$ are not found with chronic illness but $13 \%$ are with chronic illness. $75 \%$ are not having any psychological stress but $24.20 \%$ are with psychological stress. $66.40 \%$ are without social stress but $33.60 \%$ are with social stress.

In B G. Prasad's socioeconomic scale $45 \%$ are coming under class 2 [upper middle class] and $5.60 \%$ are under class 4 [lower middle class]. In CAGE questionnaire, $72.40 \%$ are found with alcohol use while $27.60 \%$ are not. In severity alcohol dependence questionnaire, $72 \%$ are with mild dependence while $13.20 \%$ are with severe dependence.

\begin{tabular}{|c|c|c|c|}
\hline Sl. No. & Variables & Frequency & Percentage \\
\hline \multirow{5}{*}{1} & Age & & \\
\hline & $13-18$ & 49 & 9.80 \\
\hline & $19-35$ & 137 & 27.40 \\
\hline & $36-50$ & 147 & 29.40 \\
\hline & Above 50 & 167 & 33.40 \\
\hline \multirow{3}{*}{2} & Locality & & \\
\hline & Rural & 485 & 97.00 \\
\hline & Urban & 15 & 3.00 \\
\hline \multirow{5}{*}{3} & Education & & \\
\hline & Illiterate & 192 & 38.40 \\
\hline & Primary (up to $8^{\text {th }}$ ) & 146 & 29.20 \\
\hline & Secondary (up to $12^{\text {th }}$ ) & 113 & 22.60 \\
\hline & Degree & 49 & 9.80 \\
\hline \multirow{5}{*}{4} & Occupation & & \\
\hline & Unemployed & 106 & 21.20 \\
\hline & Unskilled & 383 & 76.60 \\
\hline & Skilled & 8 & 1.60 \\
\hline & Professional & 3 & 0.60 \\
\hline \multirow{3}{*}{5} & Marital Status & & \\
\hline & Married & 119 & 23.80 \\
\hline & Unmarried & 381 & 76.20 \\
\hline \multirow{12}{*}{6} & Biological Stress & & \\
\hline & (i) Family H/o Alcohol & & \\
\hline & Yes & 308 & 61.60 \\
\hline & No & 192 & 38.40 \\
\hline & (ii) Mental illness & & \\
\hline & No & 409 & 81.80 \\
\hline & Depression & 78 & 15.60 \\
\hline & Anxiety & 13 & 2.60 \\
\hline & Schizophrenia & .0 & 0 \\
\hline & (iii) Chronic illness & & \\
\hline & Yes & 65 & 13.00 \\
\hline & No & 435 & 87.00 \\
\hline \multirow{3}{*}{7} & Psychological Stress & & \\
\hline & Yes & 121 & 24.20 \\
\hline & No & 379 & 75.80 \\
\hline \multirow{3}{*}{8} & Social Stress & & \\
\hline & Yes & 168 & 33.60 \\
\hline & No & 332 & 66.40 \\
\hline \multirow{6}{*}{9} & $\begin{array}{c}\text { B.G. Prasad's Socioeconon } \\
\text { Class }\end{array}$ & & \\
\hline & $7008 \&$ above & 165 & 31.20 \\
\hline & $3504-7007$ & 225 & 45.00 \\
\hline & $2102-3503$ & 48 & 9.60 \\
\hline & $1051-2101$ & 28 & 5.60 \\
\hline & 1050 and below & 43 & 8.60 \\
\hline \multirow{3}{*}{10} & Cage Questionnaire & & \\
\hline & No & 138 & 27.60 \\
\hline & Yes & 362 & 72.40 \\
\hline \multirow{4}{*}{11} & $\begin{array}{c}\text { Seventy Alcohol Depender } \\
\text { Questionnaire }\end{array}$ & & \\
\hline & Mild Dependence & 360 & 72.00 \\
\hline & Moderate Dependence & 74 & 14.80 \\
\hline & Severe Dependence & 66 & 13.20 \\
\hline
\end{tabular}

\begin{tabular}{|cccc|}
\hline \multicolumn{5}{c|}{ Alcohol Dependence (Audit Category) } \\
Age & No (\%) & Yes (\%) & Total (\%) \\
$13-18$ & $29(10.36)$ & $20(9.09)$ & $49(9.8)$ \\
$19-35$ & $80(28.57)$ & $57(25.91)$ & $137(27.4)$ \\
$36-50$ & $82(29.29)$ & $65(29.55)$ & $147(29.4)$ \\
$>50$ & $89(31.79)$ & $78(35.45)$ & $167(33.4)$ \\
Total & $280(56)$ & $220(44)$ & $500(100)$ \\
Education $_{\text {Illiterate }}$ & $86(30.71)$ & $106(48.18)$ & $192(38.4)$ \\
Up to 8 $^{\text {th }}$ & $85(30.36)$ & $61(27.35)$ & $146(29.2)$ \\
${\text { Up to } 12^{\text {th }}}_{\text {Degree }^{\text {Total }}}^{71(25.36)}$ & $42(19.09)$ & $113(22.6)$ \\
\hline \multicolumn{4}{c}{ Table 2. Relationship between Age, Education } \\
\hline \multicolumn{4}{c}{ with Alcohol Dependence } \\
\hline
\end{tabular}

Table 2 shows, $9.09 \%$ from ages 13 to 18 years and $35.45 \%$ are above 50 years of age are found to be Alcohol dependence and out of 500, prevalence of $44 \%$ of people are found with alcohol dependence in Coimbatore district.

$48.18 \%$ of illiterates and $5 \%$ of degree holders are found to be with alcohol dependence in Coimbatore district. 


\begin{tabular}{|ccccc|}
\hline \multicolumn{5}{c|}{ Alcohol Dependence (Audit Category) } \\
Sl. & B.G. Prasad's & No & Yes & Total \\
No. & Social Class & $\mathbf{( \% )}$ & $\mathbf{( \% )}$ & $(\%)$ \\
1 & Upper class & $92(32.86)$ & $64(29.09)$ & $156(31.20)$ \\
2 & Upper middle & $130(46.43)$ & $95(43.18)$ & $225(45.00)$ \\
3 & Lower middle & $26(9.29)$ & $22(10.00)$ & $48(9.60)$ \\
4 & Upper lower & $17(6.07)$ & $11(5.00)$ & $28(5.60)$ \\
5 & Lower & $15(5.36)$ & $28(12.73)$ & $43(8.60)$ \\
6 & Total & $\mathbf{2 8 0}$ & $\mathbf{2 2 0}$ & $\mathbf{5 0 0}$ \\
\hline Table 3. Relationship between Social Class and Alcohol Dependence \\
\hline
\end{tabular}

Table 3 shows that $43.18 \%$ of upper middle class and $5 \%$ of upper lower class are found to be with alcohol dependence.

\begin{tabular}{|ccccc|}
\hline \multicolumn{5}{|c|}{ Alcohol Dependence (Audit Category) } \\
Sl. No. & Perceived Stress & No (\%) & Yes (\%) & Total (\%) \\
1 & Low stress (0-13) & $107(38.21)$ & $93(42.27)$ & $200(40.00)$ \\
2 & Moderate stress (14-26) & $164(58.57)$ & $111(50.45)$ & $275(55.00)$ \\
3 & High stress (27-40) & $9(3.21)$ & $16(7.27)$ & $25(5.00)$ \\
$\mathbf{4}$ & Total & $\mathbf{2 8 0}$ & $\mathbf{2 2 0}$ & $\mathbf{5 0 0}$ \\
\hline \multicolumn{5}{|c}{ Table 4. Relationship between Perceived Stress Scale } \\
and Alcohol Dependence \\
\hline
\end{tabular}

Table 4 reveals $50.45 \%$ of people with moderate stress and $7.27 \%$ of people with high stress are found to be with alcohol dependence.

\begin{tabular}{|c|c|c|c|c|c|c|}
\hline & & Prevale & nce of Exp & ssures & & \\
\hline & & 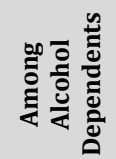 & 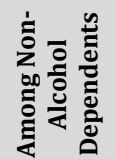 & & & \\
\hline $\begin{array}{l}\text { Sl. } \\
\text { No. }\end{array}$ & $\begin{array}{c}\text { Exposures } \\
\text { Characteristics }\end{array}$ & $\begin{array}{c}\text { Number } \\
(\%)\end{array}$ & $\begin{array}{c}\text { Number } \\
(\%)\end{array}$ & $\begin{array}{l}\text { Odds } \\
\text { Ratio }\end{array}$ & $\begin{array}{c}95 \% \\
\text { Confidence } \\
\text { Interval }\end{array}$ & $\begin{array}{c}P \\
\text { Value }\end{array}$ \\
\hline 1 & Age $<40$ yrs. & $95(43)$ & $136(49)$ & 0.8 & 0.6 to 1.1 & 0.23 \\
\hline 2 & Family History & $159(72)$ & 149 (53) & 2.3 & 1.6 to 3.3 & $0.00001^{*}$ \\
\hline 3 & Chronic illness & 41 (19) & $24(9)$ & 2.4 & 1.4 to 4.2 & 0.0009 \\
\hline 4 & Locality Urban & $5(2)$ & $10(4)$ & 0.6 & 0.2 to 2.1 & 0.44 \\
\hline 5 & Married & $176(80)$ & $205(73)$ & 1.5 & 0.95 to 2.2 & 0.08 \\
\hline 6 & Mental illness & 35 (1) & $56(20)$ & 0.8 & 0.5 to 1.2 & 0.24 \\
\hline 7 & $\begin{array}{l}\text { Occupation } \\
\text { Unemployed }\end{array}$ & $56(25)$ & $50(18)$ & 1.6 & 1.01 to 2.4 & 0.04 \\
\hline 8 & Psychological stress & $79(36)$ & $42(15)$ & 3.2 & 2.1 to 4.9 & $0.00001^{*}$ \\
\hline 9 & Social stress & $102(46)$ & $66(24)$ & 2.8 & 1.9 to 4.1 & $0.00001^{*}$ \\
\hline & $\begin{array}{r}\text { le 5. Prevalenc } \\
\& N \mathrm{~N}\end{array}$ & $\begin{array}{l}\text { of Various } \\
\text { 1-Alcohol L }\end{array}$ & $\begin{array}{l}\text { Exposur } \\
\text { ependen }\end{array}$ & Imo & $\begin{array}{l}\text { Alcohol De } \\
\text { tudy }\end{array}$ & endents \\
\hline & $<0.05$ are cons & & & & & \\
\hline
\end{tabular}

Table 5 shows that people with family history [biological/physiological stress] and people with psychological stress and people with social stress are having statistical significance with alcohol dependence.

\section{DISCUSSION}

On the basis of the [NFHS] National Family Health Survey which was done among the population had reported around $9.4 \%$ of adult [15 - 54 years of age] were drinking alcohol almost every day. Few studies have used tools such as AUDIT questionnaire to detect harmful use and alcohol dependence among alcohol users. ${ }^{[4]}$

The study done in Kolkata among male alcohol users using audit tool, reported that $8 \%$ of them were found with harmful alcohol consuming pattern and $14 \%$ were with alcohol dependence.[6] Studies from India and other south Asian countries have acknowledged that people with "harmful use" of alcohol ranges from $15.6 \%$ to $34.8 \% .^{[7,8,9,10]}$
The studies had reported that individuals who initiate to consume alcohol before 21 years of life, with low education or illiteracy and people with smoking habit, spending more money per day on alcohol and having a family history of consuming alcohol, have increased risk of harmful alcohol intake. ${ }^{[8]} \mathrm{A}$ study done in the rural area of south India reported that the risk of harmful consequences due to intake of alcohol is high in those villages were the illicit alcohol is made locally.

Age and gender differences in alcohol consumption pattern is well documented. The Meta-analysis by Reddy and Chandrasekar revealed a 10 -fold difference in rates of alcohol intake between men and women [men 11.9/1000 population and women 1.7/1000 population.[11] Almost all studies reported higher use of alcohol among men ranging from $26 \%$ to $72 \% .{ }^{[12,13]}$ National Family Health Survey (NFHS) 3 has reported that $32 \%$ of men and $2 \%$ of women consumed alcohol.[14] Over all the age range at initiation of drinking was found to be 20-29 years in different studies, despite the wide differences found among regions, populations and years of studies.[15,16] Males with higher AUDIT scores had lower out of pocket expenditure for outpatient care, in contrast to the increased health care usage which has been observed for people with alcohol use disorders elsewhere in India.[17]

In the current study, there is a statistical significance with Biological stress, Psychological stress and Social stress with alcohol dependence. There is no statistical significance in age for alcohol dependence, but people of $>50$ years of age are found with alcohol dependence. Illiterates are found more with alcohol dependence, upper middle socio-economic class are more with alcohol dependence, person with moderate stress level are more with alcohol dependence. The strengths of this study are follows: First, to our knowledge this is the first study to reporting alcohol dependence among males in Coimbatore district in Tamilnadu. Second, in our present study we used the widely accepted AUDIT tool to confirm harmful alcohol use and dependence which makes the study results comparable across the world. Third, single interviewer conducted all the interviews and hence the probability of very less information bias. Fourth, it was a community-based house to house survey and all the eligible individuals were interviewed, hence the selection bias would be minimized. Fifth the associated psychiatric conditions which may have influence on the alcohol consumption were captured in this study. The limitations in this study are the follows: As the prevalence are more in males when compared to females in previous studies, we focused mainly on males in our study. As it is a cross sectional study, some recall bias might have occurred and so need retrospective studies in this area in future to overcome these biases.

\section{CONCLUSIONS}

The common reason for various patterns of alcohol use which are detrimental to health, social and psychological wellbeing and societal wellbeing, is the unrestricted availability and easy accessibility to alcohol. Global evidence indicates restricting supply with respect to age, number of drinks, context of use contributes to reducing harm from alcohol use and also strict enforcement of legislation pertaining to drinking and driving, interpersonal violence, and restricting retail venders will 
surely reduce the supply and acute consequences of alcohol use both for patient's health and society.[18]

Variation in the consumption patterns in different socioeconomic groups are vital to formulate clearly defined strategies for both demand and supply reduction and to organize required services in general and specific populations. Health promotion activities such as community level awareness regarding ill effects of alcohol should be conducted. Legal limits for alcohol intake should be put in place.

Financial or Other Competing Interests: None.

\section{REFERENCES}

[1] Das SK, Balakrishnan V, Vasudevan DM. Alcohol: Its health and social impact in India. Natl Med J India 2006;19(2):94-9.

[2] Problems related to alcohol consumption. Report of a WHO expert committee. World Health OrganTech Rep ser 1980;650:1-72.

[3] Girish N, Kavitha R, Gururaj G, et al. Alcohol use and implications for public health: patterns of use in four communities. India J Community Med 2010;35(2):23844.

[4] WHO. Global status report on alcohol and health. Geneva: World Health Organisations 2014.

[5] WHO Expert committee on problems related to alcohol consumption: second report WHO regional office for the western pacific. World Health Organization 2007.

[6] Ghosh S, Samanta A, Mukherjee S. Patterns of alcohol consumption among male adults at a slum in Kolkata, India. J Health Popul Nutr 2012;30(1):73-81.

[7] Gupta A, Priya B, Williams J, et al. Intra-household evaluation of alcohol abuse in men with depression and suicide in women: a cross sectional community-based study in Chennai, India. BMC Public Health 2015;15:636.
[8] Kim S, Rifkin S, John SM, et al. Nature, prevalence and risk factors of alcohol use in an urban slum of southern India. Natl Med J India 2013;26(4):203-9.

[9] Kumar GS, Premarajan KC, Subitha L, et al. Prevalence and pattern of alcohol consumption using alcohol use disorders identification test [AUDIT] in rural Tamil Nadu, India. J Clin Diagn Res 2013;7(8):1637-9.

[10] Kumar AM, Ramaswamy G, Majella MG, et al. Alcohol, harmful use and dependence: assessment using the WHO alcohol use disorder identification test tool in a south Indian fishermen community. Ind Psychaitry J 2018;27(2):259-3.

[11] Hawks D. Prevention of psychoactive substance use: a selected review of what works in the area of prevention. World Health Organization 2002.

[12] Reddy MV, Chandrasekar CR. Prevalence of mental and behavioural disorders in India: a meta analysis. Indian J Psychiatry 1998;40(2):149-57.

[13] Dhupdale NY, Motghare DD, Ferreira MA, et al. Prevalence and pattern of alcohol consumption in rural, Goa. Indian J Community Med 2006;31(2):104-5.

[14] Rathod SD, Nadkarni A, Bhana A, et al. Epidemiological features of alcohol use in rural India: a population based cross-sectional study. BMJ Open 2015;5:e009802.

[15] Meena, Khanna P, Vohra AK, et al. Prevalence and pattern of alcohol and substance abuse in urban areas of Rohtak city. Indian J Psycjiatry 2002;44(4):348-52.

[16] Anand K. Assessment of burden and surveillance of major non-communicable diseases in India. South East Asia Regional Office, workshop document. New Delhi: World Health Organisation 2000.

[17] Deswal BS, Jindal AK, Gupta KK. Epidemiology of alcohol use among residents of remote hills of Arunachal Pradesh. Indian J Community Med 2006;31(2):88-9.

[18] Dutta R, Gnanasekaran S, Suchitra S, et al. A population based study on Alcoholism among adult males in a rural area, Tamil Nadu, India. J Clin Diagn Res 2014;8(6):JC1-3. 